\title{
Tiny percutaneous needle biopsy: An efficient method for studying cellular and molecular aspects of skeletal muscle in humans
}

\author{
TIZIANA PIETRANGELO ${ }^{1 *}$, LUIGI D'AMELIO ${ }^{2 *}$ CHRISTIAN DORIA $^{1}$, ROSA MANCINELLI $^{1}$, \\ STEFANIA FULLE ${ }^{1}$ and GIORGIO FANÒ ${ }^{1}$ \\ ${ }^{1}$ Department of Neurosciences and Imaging, Clinical Research Center (CRC) d'Annunzio Foundation, Interuniversity \\ Institute of Myology (IIM), University 'G. d'Annunzio' Chieti-Pescara, Via dei Vestini, I-66100 Chieti; \\ ${ }^{2}$ Orthopedics and Traumatology Unit, San Liberatore Hospital of Atri, Teramo, Italy
}

Received September 6, 2010; Accepted November 1, 2010

DOI: $10.3892 / \mathrm{ijmm} .2010 .582$

\begin{abstract}
Needle biopsy is widely used to obtain specimens for physiological, anatomical and biochemical studies of skeletal muscle (SM). We optimized a procedure which we termed tiny percutaneous needle biopsy (TPNB), to efficiently gather good numbers of human satellite cells and single dissociated fibers for the functional study of skeletal muscle; these samples permit isolation of high-quality RNA and sufficient amounts of proteins to allow molecular analysis. Moreover, TPNB showed a clear advantage in that the technique was easier than other procedures used on healthy volunteers in human trials. TPNB is a very safe minor surgical procedure. It is less traumatic than needle aspiration biopsy, and significant complications are improbable. TPNB should become established as an important tool in the investigation of SM and may be employed to study various physiological aspects of SM in human subjects. We suggest that TPNB should also be used in the study of muscle diseases and disorders including muscular dystrophy, congenital myopathy, and metabolic defects.
\end{abstract}

\section{Introduction}

Molecular and cellular studies on the skeletal muscle (SM) of humans have been conducted for many years using samples obtained principally from the Vastus Lateralis (VL) muscle. Classically, muscle biopsy is an open procedure in which

Correspondence to: Dr Tiziana Pietrangelo, Department of Neurosciences and Imaging, University 'G. d'Annunzio' ChietiPescara, Via dei Vestini 29, I-66013 Chieti, Italy

E-mail: tiziana@unich.it

${ }^{*}$ Contributed equally

Key words: human satellite cells, fibers, transcriptional profile both the skin and the muscle are cut by a scalpel. Next, a needle connected to a vacuum pump is inserted to aspirate muscle tissue (1-3). This technique is still applied in most muscle laboratories (4), and is termed needle aspiration biopsy (NAB). Today, other biopsy techniques are also used to obtain muscle samples prior to genetic (5) and enzymatic (6) analyses. Studying muscle for many years, we have devoted attention to human SM, particularly in efforts to study the muscle's regenerative capacity at different ages and to evaluate the contribution of oxidative stress to regulation of sarcopenia (7-10). In these works, we have used human VL or Gluteus Medium muscle samples obtained during orthopedic surgery or by employing NAB with application of Liverpool or Edwards needles, as described by Dietrichson et al (11) and Edwards (3).

In the past 4 years we have developed a multidisciplinary project exploring SM adaptation of young and elderly people to different training regimens. In this work, it was necessary to perform at least two muscle biopsies (before and after training), and sometimes three (an extra biopsy on followup), to compare data from the same muscle over time. In particular, our interest has been focused on the fiber regeneration due to the activation of adult stem cells of the SM, the satellite cells (SC) $(12,13)$. Most potential subjects who were interviewed declined to participate in the project because they feared the discomfort associated with NAB.

To solve this problem, we decided to test a Tru-Cut semiautomatic needle for use in SM needle biopsy. This device has already been employed to sample various tissues including the liver, the mammary gland, the breast, the prostate (14-16), and the muscle (17). Indeed, Magistris et al (18), used an automatic biopsy device to sample SM in the course of histological and genetic studies. Encouraged by the fact that this technique was largely used, and also because consent to the procedure was readily obtainable from both young and elderly volunteers, we evaluated the use of a tiny biopsy needle to study cellular and molecular aspects of SM in both the young and the elderly. We decided to use a semi-automatic device featuring a 13-gauge needle. We modified and optimized the procedure and here term the technique tiny percutaneous needle biopsy (TPNB). 
Table I. Anthropometric data of young and elderly volunteers.

\begin{tabular}{|c|c|c|c|c|c|}
\hline & Age (years) & Height (m) & Weight $(\mathrm{kg})$ & $\%$ Body fat & Isometric force $(\mathrm{N})$ \\
\hline \multicolumn{6}{|l|}{ TPNB } \\
\hline Old male $(n=8)$ & $64.1 \pm 1.2$ & $1.70 \pm 0.04$ & $72.9 \pm 3.9$ & $21.7 \pm 2.5$ & $734.8 \pm 68.1$ \\
\hline Young male $(n=5)$ & $38.6 \pm 5.6$ & $1.70 \pm 0.04$ & $77.4 \pm 7.1$ & $23.4 \pm 2.6$ & $1,076.2 \pm 68.8$ \\
\hline Old female $(n=2)$ & $65.5 \pm 0.5$ & $1.50 \pm 0.07$ & $79.5 \pm 14.3$ & $36.7 \pm 8.2$ & $322.0 \pm 43.0$ \\
\hline Young female $(n=2)$ & $40.0 \pm 2.0$ & $1.74 \pm 0.07$ & $58.8 \pm 5.0$ & $31.3 \pm 5.0$ & $404.0 \pm 54.0$ \\
\hline \multicolumn{6}{|l|}{ NAB } \\
\hline Old male $(n=5)$ & $70.8 \pm 1.1$ & $1.67 \pm 0.05$ & $74.3 \pm 7.03$ & $28.2 \pm 2.8$ & $593.0 \pm 86.3$ \\
\hline Young male $(n=5)$ & $37.2 \pm 3.0$ & $1.70 \pm 0.03$ & $77.1 \pm 6.6$ & $26.1 \pm 2.3$ & $907.7 \pm 37.7$ \\
\hline Old female $(n=2)$ & $60.5 \pm 7.5$ & $1.57 \pm 0.05$ & $55.2 \pm 2.2$ & $35.4 \pm 4.7$ & $325.3 \pm 45.3$ \\
\hline Young female $(n=5)$ & $42.7 \pm 3.5$ & $1.60 \pm 0.06$ & $70.5 \pm 13.3$ & $35.7 \pm 7.2$ & $442.0 \pm 47.0$ \\
\hline
\end{tabular}

The table shows the means (with standard errors) of age, height, weight, \% body fat, and isometric strength peak measured in the dominant leg of young and elderly male and female volunteers.

In the present report, we describe this easy method, and compare the results obtained from TPNB samples with those from tissue harvested using NAB. We focus particularly on SC recovery and RNA and protein yield.

\section{Materials and methods}

Subjects. We enrolled 34 volunteers 20-75 years of age to obtain either NAB or TPNB samples as part of a study on SM adaptation. Each subject was randomly selected to undergo a specific needle biopsy procedure, NAB or TPNB, as shown in Table I, which also contains anthropometric data. Each subject provided written informed consent for both NAB and TPNB. The study was approved by the Ethics Committee of the University G. d'Annunzio Chieti-Pescara, Chieti, Italy (protocol nos. 1233/06 COET dated 25 July 2006; 1884 COET dated 15 May 2009; and 1634/08 COET dated 24 June 2008). Sampling was performed at the Clinical Research Center of the G. d'Annunzio Foundation.

TPNB and NAB devices. A Precisa needle model 1310 (HS Hospital Service SpA, Latina, Italy) of a 13-gauge diameter and with an insertion cannula $100 \mathrm{~mm}$ in length, was used (Fig. 1). This is a semi-automatic needle in which a cannula contains the outer rod and an inner notched cylinder permitting unhooking, and is used to cut, trap, and withdraw a tissue sample. A spring system allows automatic advancement of the inner notched cylinder within the external cylinder inserted into the skin; the inner cylinder travels below the fascia and into the muscle. Insertion depth can be monitored by reference to notches in the external cannula (Fig. 1). We termed this procedure TPNB, to distinguish it from NAB. In general, the TPNB procedure consists of insertion of the needle into the muscle (without cutting the skin with a scalpel), triggering of the spring (the inner cannula is now inserted into the muscle to a depth of 2-3 cm), release of the outer cannula (which works like a guillotine to cut the muscle fibers), extraction of the inner cannula (Fig. 1) and retrieval of the muscle piece in a sterile manner. It is important to note that TPNB permits multiple sampling if the outer cannula remains inserted into the tissue, because the inner cannula can simply be removed and re-inserted. Each stick-shaped piece of SM is removed from the notch of the inner rod using sterile tweezers, collected into an appropriate solution, and either immediately delivered to the laboratory for examination according to a specific protocol or properly stored.

An Edwards needle (Fig. 1) is composed of four parts: an outer cannula with a grooved window at the tip, an inner tube or guillotine, a cylinder through which muscle is pulled out of the inner tube at the conclusion of sampling, and a vacuum pump. The needle is passed through a skin incision and next through the fascia, with the aperture closed. When the muscle is entered, the aperture is opened by withdrawal of the inner tube, and next closed, trapping a sample of muscle in the barrel. Aspiration using a vacuum pump is essential to trap muscle in the groove of the outer cannula prior to cutting with the guillotine (11). The TPNB procedure is also cheaper than the NAB procedure. In fact, the TPNB needles were sterile disposable while the Edwards needle are handmade devices that have to be cleaned, sterilized, made RNAse and protein free prior to each use (a time consuming preparation procedure).

Surgical aspects. TPNB is usually performed under local anesthesia employing $2 \mathrm{ml}$ xylocaine (1-2\%, v/v) after skin sterilization with Betadine. The needle direction is commonly perpendicular to the VL upon piercing of the fascia and insertion is in the muscle belly. Each muscle sample is obtained by release of a trigger that unloads the spring and activates the needle. The entire procedure can be performed using one hand and takes a few seconds.

Injection of an anesthetic may cause a brief burning or stinging sensation before the area becomes numb. After the anesthetic wears off, the area may be sore for some hours, or (rarely) for 1-2 days. Usually, minimal or no discomfort is experienced during biopsy. A sensation of pressure or tugging 


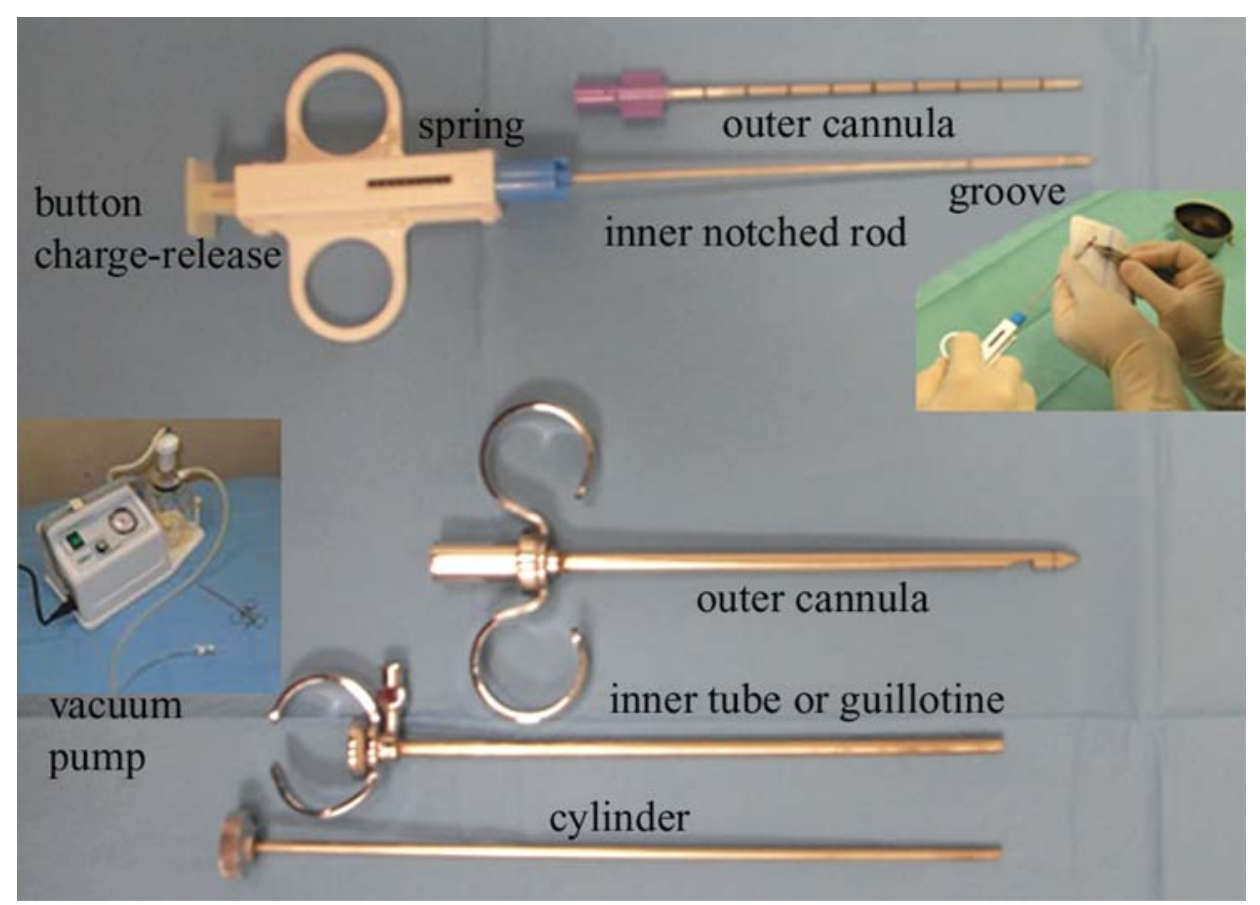

Figure 1. The Precisa 1310 and Edwards needles used for the tiny percutaneous needle biopsy (TPNB) and needle aspiration biopsy (NAB), respectively. The Precisa 1310 has two parts: an outer cannula $10 \mathrm{~cm}$ in length and an inner notched rod with a groove $2 \mathrm{~cm}$ deep. The Edwards needle has four parts: an outer cannula, an inner tube, a vacuum pump (insert), and a cylinder to be inserted in the inner tube. The Precisa 1310 is a unique device with a spring to tension the external cannula (permitting incision to a depth of 1-2 cm) and a button which, when pressed, allows the cannula to spring up. This maneuver traps muscle into the groove ( $2 \mathrm{~cm}$ in maximal length) that is carved into the inner cylinder (the notched inner rod). The Edwards needle is connected via a pipe to a vacuum pump. An applied suction of $1.5 \mathrm{~atm}$ ensures insertion of muscle into the groove (near the tip of the outer cannula shown in the figure). Next, the guillotine cuts the muscle. The insert in the left shows the vacuum pump used for NAB. The insert in the right shows the VL fibers obtained by sampling, after the inner cannula has been extracted through the outer cannula.

may be reported. As with any surgical procedure, complications are possible. Fortunately, major complications after TPNB are uncommon. Bleeding after the extraction of the needle is the most usual complication and a slight bruise may rarely be evident. Infection is a rare complication that readily responds to treatment.

Patient preparation before TPNB is routine, including: i) no use of aspirin or aspirin substitutes (e.g. ibuprofen, naproxen) for 1 week before the procedure, ii) no food for a few hours prior to the procedure, iii) completion of routine blood tests, including a clotting profile, 2 weeks before the biopsy, iv) suspension of blood anticoagulant medications, and perhaps, v) institution of antibiotic prophylaxis. The physician has ascertained that the patient has not had an allergic reaction to the anesthetic.

Before TPNB, vital signs (e.g., pulse, blood pressure, and temperature) should be measured. The skin above the area to be biopsied, previously depilated and outlined with a dermographic pen, is swabbed with an antiseptic solution and draped with sterile surgical towels. The skin may be numbed with a local anesthetic. We do not consider it necessary to inject anesthetic into the muscle because TPNB does not cause muscle pain and any possible chemical artifacts caused by anesthetic are avoided. Biopsy of the VL muscle is performed at a level about one-third of the distance from the upper margin of the patella to the trochanter major. The choice of this position was motivated by anatomical considerations; the area lacks significant neurovascular structures. The needle is inserted perpendicularly to the skin, and entry into the muscle is accompanied by a slight resistance that can be felt by the operator. To verify the depth to which the needle is inserted, it is useful to refer to the scale rod on the cannula (Fig. 1). Echographic assistance is necessary in patients with severe muscle atrophy.

After removal of the outer cannula, sterile gauze bathed in Betadine is applied to the wound for 5-10 min to prevent bleeding. Next, a simple adhesive bandage is placed to protect the insertion point. Patients are advised to avoid strenuous activity for the next 1-2 days.

Human satellite cells. Muscle tissue was collected in a sterile manner using tweezers and was placed into $10 \mathrm{ml}$ amounts of sterile medium containing HAM's F-10 medium (Gibco, Grand Island, NY) supplemented with $50 \mathrm{mg} / \mathrm{ml}$ gentamycin, at $4^{\circ} \mathrm{C}$ or on ice. Each sample was stored for a maximum of $24 \mathrm{~h}$ at $4^{\circ} \mathrm{C}$ followed by treatment to obtain the explants. SM fragments were manually minced and cultured in plates. Seven to thirteen days later, the first mononucleated cells migrated out of explants adherent to plates (9). The explants were removed from the plates and the cells were counted. At the first cell passage (when explants were removed), all cell populations were regarded as being at the one population doubling level. The number of myogenic cells as a proportion of the entire cellular population was evaluated at this stage. The myogenic purity of SC populations was calculated using desmin as a marker, the expression of which was determined 
using the D33 antibody (Dako; 1/50 dilution), followed by immunostaining with a biotin/streptavidin complex (Dako), as described by Fulle et al (9).

RNA extraction. SM samples were stored in 2X Lysis Buffer (Applied Biosystems, Foster City, CA) and transported to the laboratory at $-20^{\circ} \mathrm{C}$. Samples were frozen in Lysis Buffer at $-80^{\circ} \mathrm{C}$ or immediately homogenized for $3-5 \mathrm{~min}$ in $1 \mathrm{ml}$ TRIzol/50 mg tissue (Invitrogen/Life Technologies) using an Ultra-Turrax-T8 homogenizer (IKA-Werke, Staufen, Germany). Total RNA was purified following the standard TRIzol protocol. Small aliquots of RNA were used both for quantification and for quality control. High-quality RNA was processed. RNA aliquots of $2 \mu \mathrm{g}$ were used for amplification and labeling prior to application to a high-density oligonucleotide microarray $(10,17,23)$. Aliquots of $2 \mu \mathrm{g}$ RNA were used for retrotranscription and loading to multigene arrays prior to PCR analysis (Applied Biosystems/Life Technologies; array no. 4342253).

Protein examination. Tissue samples were dissolved in Laemmli's solution prior to electrophoretic separation $(7,17)$. Immunoblotting was performed on proteins (50 $\mu \mathrm{g}$ samples) resolved by $6 \%(\mathrm{w} / \mathrm{v})$ SDS-PAGE (7). Specific proteins were immunologically detected and transferred to nitrocellulose membranes using a semi-dry blotting apparatus. The transfer current was $500 \mathrm{~mA}$ and the transfer time depended on the protein sample under analysis. Immunoreactive proteins were detected using an enhanced chemiluminescence technique (ECL kit; Amersham Pharmacia Biotech) and quantified by densitometry (Imagemaster IM1D, Amersham Pharmacia Biotech).

Statistical analyses. Data are expressed as means \pm standard errors. The unpaired Student's t-test, with application of Welch's correction were used to calculate statistical significance. The Prism5 GraphPad software (Abacus Concepts, GraphPad Software, San Diego, CA) was employed for statistical analyses. A p-value $<0.05$ was considered to indicate statistical significance.

\section{Results}

Beginning in 2007, and encouraged by the feasibility of the TPNB procedure, its efficiency in terms of the amounts of muscle obtained, and the ease of obtaining informed subject consent, we proposed the use of TPNB instead of NAB to subjects whom we interviewed and enrolled an increasing number of both young and elderly volunteers (currently more than 34 subjects) in our studies. When the Edwards NAB and the TPNB procedures are compared, important differences come out. The first observation is that NAB yielded $55 \pm 15 \mathrm{mg}$ SM that we were accustomed to subdividing into samples for different experimental tests. Indeed, when muscle samples were obtained using the NAB procedure, each individual sample was placed on a sterile surface or into a Petri-dish and manually subdivided. This caused several problems, including stretching of the fibers, and an increased probability of loss of sterility. A muscle sample obtained by NAB is like a cube with an $\sim 3.5-4.1 \mathrm{~mm}$ side and an area of $\sim 15 \mathrm{~mm}^{2}$. Such a sample is difficult to subdivide along the run of the fibers because of fiber refolding.

Using TPNB, we obtained several sticks of muscle and each stick weighed $8 \pm 3 \mathrm{mg}$. After 4-5 consecutive samplings, we had a total of about 45-55 mg of SM already subdivided into individual fragments. Thus, we did not need to divide individual muscle samples. Each sample was a cylinder with a diameter of approximately 0.9-1.1 mm, with a cross-sectional area of approximately $0.6 \mathrm{~mm}^{2}$ and a length of about $8-10 \mathrm{~mm}$, corresponding to the length of the notch on the inner rod. Despite the small diameter, TPNB specimens are of adequate size and of good quality.

Our projects feature four different levels of SM investigation, requiring collection of sufficient muscle amounts. First we need to obtain a good number of SC that will be employed in exploration of SM regeneration. Secondly, the muscle amount needs to be sufficient to permit recovery of single fibers of a length useful in mechanical studies and thirdly to afford good sample purity facilitating RNA extraction for genetic and transcriptome analyses. Finally, the amount should be sufficient to yield good quality protein samples permitting evaluation of the proteome.

TPNB allows multiple sampling to be performed; the outer cannula is simply left in place and the inner cannula can be removed and re-inserted several times into the same muscle site of the same subject. This is useful in studies with elderly people who show SM atrophy. We have successfully obtained SM samples adequate for all of our different experimental protocols. For our work on regeneration, we routinely obtain $4,500.0 \pm 774.6 \mathrm{SC} / \mathrm{mg}$ of young human male and female $\mathrm{SM}$ and $7,037.5 \pm 2,769.1 \mathrm{SC} / \mathrm{mg}$ of elderly human male and female SM (from each stick of VL weighing about $10 \mathrm{mg}$ ). The SC numbers from NAB sampling average 2,183.8 \pm 617.6 $\mathrm{SC} / \mathrm{mg}$ young human male and female SM and 1,551.8 \pm 489.3 $\mathrm{SC} / \mathrm{mg}$ of elderly human male and female SM (from each sample of VL weighing about $30 \mathrm{mg}$ ). TPNB yields significantly higher numbers of SC from young male and female volunteers compared to the cell numbers obtained using NAB ( $p=0.04)$; whereas, the numbers of SC obtained from elderly muscles although somewhat higher by TPNB compared to NAB, do not significantly differ between the two techniques $(\mathrm{p}=0.09)$ (Table II).

As human SC obtained from explants are always contaminated with non-myogenic cells, we estimated the myogenic purity of our cultures by immunocytochemistry for desmin. The myogenic purity of the SC population by TPNB was $57 \pm 16 \%$, thus not differing significantly from the $52 \pm 19 \%$ purity obtained by NAB. No purity differences between young and elderly muscle samples were evident.

The procedure by which SC are obtained from human samples, involving use of an explant technique, has been described by Fulle et al (9). To explore whether TPNB yielded good numbers of SC, we compared the efficiency of TPNB with that of open surgery using an enzymatic procedure to obtain SC. We biopsied dog SM using both open surgery and TPNB, and obtained SC by enzymatic digestion $(19,20)$, thus, in a manner completely different from the explants used for processing of human samples. Sterile tissue samples of the VL (from a male dog 13 years of age) and Biceps Femoris (from an 8-month-old female dog) were obtained using TPNB. 
Table II. Data obtained from TPNB and NAB samples.

\begin{tabular}{|c|c|c|c|c|c|c|}
\hline & \multicolumn{2}{|c|}{ Number of human satellite cells/mg SM } & \multicolumn{2}{|c|}{$\mathrm{RNA} / \mathrm{SM}(\mu \mathrm{g} / \mathrm{mg})$} & \multicolumn{2}{|c|}{ protein/SM $(\mu \mathrm{g} / \mathrm{mg})$} \\
\hline & TPNB & NAB & TPNB & NAB & TPNB & NAB \\
\hline Old male & $\begin{array}{c}6,600.0 \pm 3,713.7 \\
(n=8)\end{array}$ & $\begin{array}{c}1,261.1 \pm 223.8^{*} \\
(n=5)\end{array}$ & $\begin{array}{c}1.6 \pm 0.5 \\
(n=8)\end{array}$ & $\begin{array}{c}1.9 \pm 0.5 \\
(n=5)\end{array}$ & $\begin{array}{c}551.8 \pm 21.5 \\
(n=8)\end{array}$ & $\begin{array}{c}603.7 \pm 34.5 \\
\quad(n=5)\end{array}$ \\
\hline Young male & $\begin{array}{c}3,800.0 \pm 406.2 \\
(\mathrm{n}=5)\end{array}$ & $\begin{array}{c}1,610.8 \pm 574.7^{*} \\
(n=5)\end{array}$ & $\begin{array}{c}2.06 \pm 0.9 \\
(n=5)\end{array}$ & $\begin{array}{c}2.2 \pm 0.7 \\
(n=5)\end{array}$ & $\begin{array}{c}570.0 \pm 20.9 \\
(n=5)\end{array}$ & $\begin{array}{c}550.7 \pm 25.7 \\
\quad(n=5)\end{array}$ \\
\hline Old female & $\begin{array}{c}8,350.0 \pm 2,350.0 \\
(n=2)\end{array}$ & $\begin{array}{c}2,133.3 \pm 1,539.2 \\
(n=2)\end{array}$ & $\begin{array}{c}1.9 \pm 0.8 \\
(n=2)\end{array}$ & $\begin{array}{c}1.8 \pm 0.4 \\
(n=2)\end{array}$ & $\begin{array}{c}543.5 \pm 36.1 \\
(n=2)\end{array}$ & $\begin{array}{c}580.7 \pm 30.6 \\
\quad(n=2)\end{array}$ \\
\hline Young female & $\begin{array}{c}6,120.0 \pm 2,200.0 \\
(n=2)\end{array}$ & $\begin{array}{c}3,330.0 \pm 1,330.0 \\
(n=5)\end{array}$ & $\begin{array}{c}1.7 \pm 0.0 \\
(n=1)\end{array}$ & $\begin{array}{c}1.7 \pm 0.4 \\
(n=5)\end{array}$ & $\begin{array}{c}469.8 \pm 0.0 \\
\quad(n=1)\end{array}$ & $\begin{array}{c}621.7 \pm 42.9 \\
\quad(n=5)\end{array}$ \\
\hline
\end{tabular}

The first part of the table shows the numbers of human satellite cells obtained using tiny percutaneous needle biopsy (TPNB) and needle aspiration biopsy (NAB), from male and female, young and old, volunteers. The central part of the table shows the yields of RNA, and the last part of the table the amounts of protein, per mg of Vastus Lateralis (VL). Data are reported as means with standard errors. T-test analysis showed that the number of SC obtained using TPNB vs. the number of SC obtained using NAB were significantly different when comparing old to young males $\left({ }^{*} \mathrm{p}<0.05\right)$.

Sample weights were $30 \pm 3 \mathrm{mg}$. Sterile muscle tissue samples of the Rectus Abdominus (1-year-old female dog) and Gluteus Superficialis (3-year-old female dog) were obtained by open surgery. The weights of these samples were $100 \pm 13 \mathrm{mg}$. We obtained $352 \mathrm{SC} / \mathrm{mg}$ VL from the 13-year-old dog and $755 \mathrm{SC} / \mathrm{mg}$ Biceps Femoris from the 8-month-old dog by TPNB, and $110 \mathrm{SC} / \mathrm{mg}$ Rectus Abdominus from the 1-yearold dog and $300 \mathrm{SC} / \mathrm{mg}$ Gluteus Superficialis from the 3-yearold dog by open surgery. Although dogs showed differences in SC yield with age and muscle type, the numbers of cells obtained using TPNB and open surgery did not differ significantly, although the cell numbers obtained by TPNB were somewhat higher than those yielded by open surgery.

Collaborators of Professor Carlo Reggiani in the University of Padua, where the mechanical experiments on single fiber were performed, were able to obtain approximately 500 dissociated fibers from each TPNB sample of either young or elderly subjects. A high percentage of such fibers were of lengths greater than $0.5 \mathrm{~mm}$, permitting use of the fibers in single-fiber mechanical experiments.

We extracted about 15-20 $\mu \mathrm{g}$ high-quality RNA from each TPNB sample. Table II shows the yields from different types of samples. This amount of RNA was adequate for amplification and retrotranscription prior to microarray work, and permitted protocol validation before use of the polymerase chain reaction. The difference between RNA content on muscle samples taken by TPNB and NAB was not significant. We extracted about 4-6 mg of total proteins from each TPNB sample (details in Table II). Proteins prepared from TPNB samples were subjected to gel electrophoresis and Western blotting. Notably, residual samples after single-fiber dissection could also be used in protein analysis, as described in Materials and methods) $(7,17)$. Our collection procedure facilitated the initial homogenization required for protein solubilization, and we thus obtained protein quantities that were more than sufficient for electrophoresis and subsequent immunoblotting.
The difference between protein content of muscle samples taken by TPNB and NAB was not significant.

\section{Discussion}

The TPNB technique has several clear advantages over the $\mathrm{NAB}$ approach, especially with respect to enhanced patient comfort and the absence of unsightly scarring. TPNB is recognized as a simple, rapid, and repeatable method useful to obtain muscle tissue; can be safely performed on an outpatient basis; and is applicable to subjects of all ages, even the sarcopenic elderly. These features are fundamentally important in our work because we can now easily enroll a large number of volunteers. In the past, it became clear to us that neither young nor elderly subjects were inclined to consent to the use of the NAB procedure. Indeed, many initially interested volunteers developed mistrust and concern, being particularly distressed when confronted with the 'huge' needle used in Edwards NAB (the adjective 'huge' was commonly used by those whom we interviewed). We became convinced that we had to employ a needle smaller in diameter than that of the Edwards NAB, but which could nonetheless give us samples of sufficient quality and quantity to further our work. We used a semi-automatic needle that had previously been employed principally in the clinical investigation of patients with mammary (15), lung (14), or prostate cancer (16) and also musculoskeletal masses (21), and to obtain samples for immunocytochemistry and immunohistochemistry. A small automatic needle had earlier been used for purification of human muscle satellite cells (18). In the cited report, it was shown that, in those with suspected muscle disease, enzymatic dissociation yielded about 1,000 myoblasts $/ 15 \mathrm{mg}$ of muscle from patients aged 40 years on average. It should be noted that the enzymatic procedure employed in the present work yielded SC numbers from dog muscle similar to the levels obtained by Magistris et al (18) 
from human SM, but our explant approach resulted in human SC numbers significantly higher than were obtained by Magistris et al (18). We selected the semi-automatic needle Precisa 1310 as a preferred device for TPNB sampling of SM. We optimized the TPNB procedure and recruited a significant number of healthy volunteers to our projects. Indeed, we are proud to report that even a top-level athlete volunteered to undergo TPNB to permit the study of the VL muscle, and that neither pain nor discomfort was experienced. Exercise physiologists are aware that it is very difficult to persuade athletes to submit to muscle biopsy, and also that it is very important to study the SM of athletes at the cellular and molecular levels to investigate muscle adaptation to different environmental conditions. In our view, TPNB optimization may be useful in the study of SM in various types of subjects, either top-level athletes, elderly subjects, or patients with muscle pathologies inducing severe atrophy and even obesity. We are of the view that TPNB may be a valuable 'field procedure'. This means that TPNB can be performed on a subject/athlete (young or elderly) immediately after a performance (obviously complying with surgical rules), because the procedure is really easy, safe and simple.

The value of the TPNB procedure lies not only in its feasibility but also in the efficiency of the approach in terms of SC yield. In particular, we demonstrated that TPNB was effective in sampling of the sarcopenic SM of elderly subjects. Sarcopenia is a condition defined by progressive atrophy of SM. It is very difficult to conduct a NAB biopsy on such muscles, whereas, TPNB is easy. We also used TPNB to explore severe atrophy of a lower limb in a young subject (29 years of age) for whom NAB was not practical. We used echographic guidance to identify and sample the VL muscle (T. Pietrangelo, personal communication). After we shared our TNPB experience with colleagues, the technique was used to sample the Latissimus Dorsi muscle, which is traditionally difficult to biopsy because the muscle is thin and flat (22).

Our results also confirm that muscle biopsy using TPNB, yields tissue susceptible to analysis of a wide range of parameters, both functional and molecular. Indeed, isolation of SC and analysis of such cells in excitation-contraction coupling experiments is one of the most important functional parameters reflecting the overall condition of SM (12). The high-level efficiency of TPNB with respect to muscle sampling is of great importance when it is sought to extend such functional analyses to (eventually) consider specific pathologies of SM. The characterization of single fiber mechanics and the identification of the fiber phenotype are also very helpful. Moreover, it is very important to adequately describe the transcriptional profiles of muscle [using oligonucleotide microarrays, as described by Pietrangelo et al $(17,23)]$, because the profile changes upon specific conditioning or under various loads in human muscles of different ages. It is also interesting to validate any profile obtained by further quantitative assessment of gene expression using, for example, multigene arrays combined with real-time PCR. Muscle protein analysis by electrophoresis and Western blotting of TPNB samples is efficient. In fact, TPNB collects muscle fibers that are devoid of fat. In rare instances, TPNB traps traces of blood vessels. Notably, the yield of SC/mg muscle was significantly higher by TPNB compared to NAB, probably because the carving of fibers was associated with a reduced level of trauma, and only minor quantities of adipose cells and vessels were collected, making the muscle tissue easily identifiable. It may also be that TPNB specifically activates migration of SC, by stimulating the synthesis of specific cytokines. We are of the view that the presence of thousands of easily dissociable fibers of 0.3-0.6 $\mathrm{mm}$ in length favor the migration of SC away from the fibers both in explants and during application of enzymatic techniques used to collect SC. Furthermore, we note the fact that while excellent for collecting satellite cells and DNA/RNA, this approach, like the standard needle biopsy, is not appropriate for in depth structural analysis. In fact, the problem in the biopsies arises from what happens as soon as the needle damage a live muscle fiber. The fiber is depolarized and it immediately contracts and quickly relaxes. However, if the fiber is not restrained it contracts to very short lengths and then it remains shortened. Moreover, the calcium diffuses in from the cut ends and it activates more contraction. The diffusion is slow $(1 \mu \mathrm{m} / \mathrm{msec})$ but it may affect a significant portion of the very short fiber segments. The fibers are usually contracted and distorted. Today, the only reliable way to obtain good samples for morphology is to do a standard biopsy in which a relatively long bundle is restrained before cutting the ends by a clamp (24) that keeps the fibers from shortening when cut, and the centers of the bundles are sufficiently far from the ends that calcium would take forever to penetrate.

In conclusion, TPNB is a very safe and minor surgical procedure. It is both less dangerous and less traumatic than $\mathrm{NAB}$, and significant complications are rare. TPNB should become established as an important tool for investigating SM and may be employed to study various physiological and pathological aspects of muscle even in fragile subjects such as the elderly. We suggest that TPNB will also be useful in the study of muscle diseases and disorders such as muscular dystrophy, congenital myopathy, and metabolic defects.

\section{Acknowledgements}

We thank Professor Clara Franzini-Armstrong for critical reading of the manuscript and for her helpful suggestions. We thank Dr S. Angelucci for information about the protein content of some muscle samples obtained using TPNB from young male subjects. We thank Alessio Pizzingrillo of the Hospital Service for his assistance. This study was supported by local grants of the University 'G. d'Annunzio' of ChietiPescara to T.P.

\section{References}

1. Bergström J: Muscle electrolytes in man: determination by neutron activation analysis on needle biopsy specimens. A study on normal subjects, kidney patients and patients with chronic diarrhoea. Scand J Clin Lab Invest 14: 1-110, 1962.

2. Costill DL, Sharp RL, Fink WJ and Katz A: Determination of human muscle $\mathrm{pH}$ in needle-biopsy specimens. J Appl Physiol 53: 1310-1313, 1982.

3. Edwards RHT: Percutaneous needle biopsy of skeletal muscle in diagnosis and research. Lancet 1: 593-595, 1971.

4. Hennessey JV, Chromiak JA, Della Ventura S, Guertin J and MacLean DB: Increase in percutaneous muscle biopsy yield with a suction-enhancement technique. J Appl Physiol 82: 1739-1742, 1997. 
5. Guescini M, Fatone C, Stocchi L, Guidi C, Potenza L, Ditroilo M, Ranchelli A, Di Loreto C, Sisti D, De Feo P and Stocchi V: Fine needle aspiration coupled with real-time PCR: a painless methodology to study adaptive functional changes in skeletal muscle. Nutr Metab Cardiovasc Dis 17: 383-393, 2007.

6. Hayot M, Michaud A, Koechlin C, Caron MA, Leblanc P, Préfaut $C$ and Maltais F: Skeletal muscle microbiopsy: a validation study of a minimally invasive technique. Eur Respir J 25: 431-440, 2005.

7. Fulle S, Belia S, Vecchiet J, Morabito C, Vecchiet L and Fanò G: Modification of the functional capacity of sarcoplasmic reticulum membranes in patients suffering from chronic fatigue syndrome. Neuromuscul Disord 13: 479-484, 2003.

8. Fulle S, Protasi F, Di Tano G, Pietrangelo T, Beltramin A Boncompagni S, Vecchiet L and Fanò G: The contribution of reactive oxygen species to sarcopenia and muscle ageing. Exp Gerontol 39: 17-24, 2004.

9. Fulle S, Di Donna S, Puglielli C, Pietrangelo T, Beccafico S, Bellomo R, Protasi F and Fanò G: Age-dependent imbalance of the antioxidative system in human satellite cells. Exp Gerontol 40: 189-197, 2005

10. Pietrangelo T, Puglielli C, Mancinelli R, Beccafico S, Fanò G and Fulle S: Molecular basis of the myogenic profile of aged human skeletal muscle satellite cells during differentiation. Exp Gerontol 44: 523-531, 2009.

11. Dietrichson P, Coakley J, Smith PEM, Griffiths RD, Helliwell TR and Edwards RH: Conchotome and needle percutaneous biopsy of skeletal muscle. J Neurol Neurosurg Psychiatry 50: 14611467, 1987.

12. Hawke TJ and Garry DJ: Myogenic satellite cells: physiology to molecular biology. J Appl Physiol 91: 534-551, 2001.

13. Lorenzon P, Bandi E, de Guarrini F, Pietrangelo T, Schäfer R, Zweyer M, Wernig A and Ruzzier F: Ageing affects the differentiation potential of human myoblasts. Exp Gerontol 39: 1545-1554, 2004.

14. Milman N: Percutaneous lung biopsy with a semi-automatic, spring-driven fine needle. Preliminary results in 13 patients. Respiration 60: 289-291, 1993

15. Nori J, Cariti G, Boeri C, Nori Bufalini F, Bianchi S, Vezzosi V and Di Lollo S: [Percutaneous biopsy in the definition of breast lesions: fine needle vs. 14-gauge]. Radiol Med 95: 630-634, 1998 (In Italian).
16. Loch AC, Bannowsky A, Baeurle L, Grabski B, König B, Flier G, Schmitz-Krause O, Paul U and Loch T: Technical and anatomical essentials for transrectal ultrasound of the prostate. World $J$ Urol 25: 361-366, 2007

17. Pietrangelo T, Mancinelli R, Toniolo L, Cancellara L, Paoli A, Puglielli C, Iodice P, Doria C, Bosco G, D'Amelio L, Di Tano G, Fulle S, Saggini R, Fanò G and Reggiani C: Effects of local vibrations on skeletal muscle trophism in elderly people: mechanical, cellular, and molecular events. Int J Mol Med 24: 503-512, 2009.

18. Magistris MR, Kohler A, Pizzolato G, Morris MA, Baroffio A, Bernheim L and Bader CR: Needle muscle biopsy in the investigation of neuromuscular disorders. Muscle Nerve 21: 194-200, 1998.

19. Greene EA and Raub RH: Procedures for harvesting satellite cells from equine skeletal muscle. J Equine Vet Sci 12: 33-35, 1992.

20. Michal J, Xiang Z, Davenport G, Hayek M, Dodson MV and Byrne KM: Isolation and characterization of canine satellite cells. In Vitro Cell Dev Biol Anim 38: 467-480, 2002

21. Welker JA, Henshaw RM, Jelinek J, Shmookler BM and Malawer MM: The percutaneous needle biopsy is safe and recommended in the diagnosis of musculoskeletal masses. Cancer 89: 2677-2686, 2000.

22. Paoli A, Pacelli QF, Toniolo L, Miotti D and Reggiani C: Latissimus dorsi fine needle muscle biopsy: a novel and efficient approach to study proximal muscles of upper limbs. J Surg Res: Jun 12, 2010 (Epub ahead of print).

23. Pietrangelo T, Toniolo L, Paoli A, Fulle S, Puglielli C, Fanò G, and Reggiani C: Functional characterization of muscle fibres from patients with chronic fatigue syndrome: case-control study. Int J Immunopathol Pharmacol 22: 427-436, 2009.

24. Engel AG: The muscle biopsy. In: Myology. 2nd edition. Engel AG and Franzini-Armstrong C (eds.) McGraw-Hill, New York, pp822-831, 1994. 